\title{
TRUNK WITH BRANCHES PUBLIC TRANSPORT LINE SCHEDULLING UNDER CONDITION OF UNIFORM HEADWAY OPERATION
}

\author{
Nikola Krstanoski ${ }^{1}$ \\ ${ }^{1}$ University "St. Kliment Ohridski", Bitola, Macedonia
}

\section{Received 13 July 2015; accepted 4 November 2015}

\begin{abstract}
Planning of public transport network for good spatial coverage may lead to an operation of radial or diametrical public transport lines that branch at one or both ends of the line. This trunk with branches operation means that all vehicles on the line serve the main - trunk section, usually covering the central area of the city, and then split in two or more branches in the peripheral areas, in order to offer better spatial service. The scheduling of this type of operation is not an easy task since only certain patterns of headways and therefore passenger demands can be met, if efficient operation under the condition of uniform headways on all sections on the line is required. In this article the author analyzes the key variables that define the uniform headway operation and establishes their relationships, thus providing answer to the question what headway patterns are feasible and if they could be acceptable for real life operation.
\end{abstract}

Keywords: public transport line scheduling, public transport line with branches.

\section{Introduction}

Radial and diametrical public transport lines are used extensively in many cities for several reasons: they trace well the directions of heavy passenger demand and they provide good connection to and from center city area. The problem that public transport planners are usually faced with, is to improve the coverage at the outbound end of these lines. A frequent solution to this problem is the concept of branching of public transport lines. A typical scenario that describes this type of operation will usually include public transport line that follows a major radial facility from the center outward, and then spread in several directions to serve larger area of lower density suburbs.
The scheduling of such lines can be done in two ways:

1. The service to each branch is treated as an independent line. The result is operation of multiple lines that have overlapping section. The headways between any two successive vehicles on the overlapping -trunk section vary.

2. A uniform headway operation is provided on the trunk and branch sections. In this case the scheduling procedure becomes more complex, since only specific patterns of headway operation and therefore specific set of passenger demand can be efficiently met if uniform headways are to be maintained at all sections of the line.

${ }^{1}$ Corresponding author: nikola.krstanoski@tfb.uklo.du.mk 
In cases when the trunk section is relatively short, and the number of public transport stops is small, the uniform headway operation on the trunk section is not important, and the first scheduling method is used.

But when the trunk section is long, with many stops, the uniform headway operation becomes important in order to avoid an uneven loading of public transport vehicles caused by the irregular headways along the trunk section. In addition to this, uneven headways may discourage some passengers due to the possible longer waiting times, despite the fact that the average headway may not be too long.

Current public transport theory has done little to clarify the conditions under which trunk/branch type of operation with uniform headways is possible and what passenger demand along the trunk and branches can be efficiently met. Some of the few works that tackle this problem are published by Vuchic (Vuchic, 2002; Vuchic, 2005) who generally describes the trunk with branches line operation, but does not analyze the condition of uniform headway operation and several authors such as Jiang and Guo (2014) and Dodson et al. (2011) who include this type of operation as possible solution to planning of public transport line network. Krstanoski (2013) opens the problem of trunk with branches operation, but here only the simplest case of a line with two branches is being analyzed. The advantages of this type of operation has been presented by Shimamoto and his co-authors (Shimamoto et al., 2012). Their model has shown much more direct connections in case of a public transport network with lines with trunk (common) section, compared to networks without such configuration. The article published by Guihaire and Hao (2008) has included examples of public transport network around the world where the concept of trunk with branches operation has been successfully applied.

The limited theoretical analysis of trunk with branches operation has forced the public transport operators to overcome the operational problems of this type from case to case, often neglecting the regularity of the headway in other to cope with the existing limitations.

The main objective of this article is to identify the key variables and their mathematical relationships that satisfy the condition of uniform headway operation on all sections of a public transport line that splits into two or more branches at its outbound end.

The expected result is to provide public transport operators with simple and efficient tool that will help working out efficient time tables in case of trunk with branches operation. In addition, this article is a challenge to mathematicians who may further develop mathematical theory initiated from the practical problem of uniform headway operation.

\section{Uniform Headway Operation on Line with Two or More Branches - Definitions, Requirements and Limitations}

The headway of operation on a public transport line is one of the most important variables that define the public transport timetables. It is defined as the time between two successive departures of public transport vehicles from the starting terminus, or simply as the time between two successive vehicles at any given point on the line.

The headway depends on the number of passengers at the maximum load section of 
the line $P_{d}$, the vehicle capacity $C_{v}$ and the level of service represented by the average vehicle occupancy a (Vuchic, 2005).

$h=\alpha \cdot C_{v} \cdot \frac{60}{p_{d}} \quad[\min ]$

The number of passengers at the maximum load section is defined by the passenger demand on a line section between those two stops where the highest number of passengers per hour occurs.

The vehicle capacity is defined as the number of spaces (seating and standing) per vehicle.

The level of public transport service is a multidimensional and complex variable. For the scheduling purpose, the average vehicle occupancy $a$ is usually taken as a measure of the level of service. The average vehicle occupancy shows the average utilization of the vehicle capacity at the maximum load section and if expressed in percents, it shows what percentage of the available spaces (seating and standing) have been occupied by passengers at most loaded section of the line.

When trunk with branches type of operation is considered, the headways between public transport vehicles at the branch sections have to correspond to the maximum passenger loads at those branches in order to achieve an efficient operation of the line. The efficient operation here is defined as an operation of a public transport line at acceptable levels of $\alpha$ at the maximum load sections.

Let's denote each branch by a capital letter A, B, C,... and so on, that is $n$ letters for $n$ branches.

The operation of a line with $n$ branches can easily be considered as operation of $n$ lines that have overlapping section (the trunk section) and independent section - the branch. Then, each line can be also denoted with the same capital letter as the corresponding branch.

The headways on each line can be denoted by $h^{A}, h^{B}, h^{C} \ldots$, while the maximum passenger loads at each branch by $P_{d}^{A}, P_{d}^{B}, P_{d}^{C}, \ldots .$.

If the ratio of the headways on each branch/ line is expressed by means of Eq. (1) then the following relation is true:

$h^{A}: h^{B}: h^{C}: \cdots=\alpha \cdot C_{v} \cdot \frac{\theta}{P_{d}^{A}}: \alpha \cdot C_{v} \cdot \frac{\theta}{P_{d}^{B}}: \alpha \cdot C_{v} \cdot \frac{\theta}{P_{d}^{C}}: \cdots$

In case of operation with vehicles with same capacity and under requirement of same level of service, the ratio (2) will become:

$h^{A}: h^{B}: h^{C}: \cdots=\frac{K}{P_{d}^{A}}: \frac{K}{P_{d}^{B}}: \frac{K}{P_{d}^{C}}: \cdots$

where $K=60 \cdot \alpha \cdot C_{v}$ is a constant.

The Eq. (3) clearly shows that patterns of passenger demand at each branch, directly determines the acceptable pattern of branch headways, if an efficient operation defined by the acceptable level of service, is to be provided. Consequently, the limited number of patterns of branch headways means a limited number of patterns for passenger demand that can be efficiently served.

Let us now focus on the determination of the number of possible headway patterns under the requirement of uniform headway operation at all sections on the line.

Since the same headway is (should be) maintained along the entire line, it is sufficient to analyze the order of departures 
from the public transport terminus at the trunk end of the line. The order of departures is given by the ordered set of capital letters that denote each line. For example, if we have a line with four branches, one possible order of departures is $\mathrm{ABCD}$, which means that first goes a vehicle on line $\mathrm{A}$, then after a time equal to headway $h$, a vehicle from line B will depart and so on. This pattern of departures repeats itself until a change of the timetable occurs due to transition from peak to off-peak period of the day (or vice versa).

The requirement of uniform headway operation at all sections of the line means that at any stop along the line the headways between two successive public transport vehicles must be uniform, regardless to which line they belong.

The simplest case of trunk with branches operation is a line with two branches. Here the solution for provision of uniform headway at all sections of the line is pretty straightforward: the vehicles at the branching point continue alternatively to each outbound terminus. They will follow the only possible pattern that allows uniform headway operation that is $\mathrm{AB} A B \mathrm{AB}$ etc.
However, as the number of branches grows, the number of patterns of departures that satisfies the uniform headway requirement increases.

Already in case of three branches there are two possible patterns of departures from terminus at the center city $\mathrm{T}$ that provide operation with uniform headways at all sections of the line.

Those patterns of departures from the center city terminus are:

$\mathrm{ABC}, \mathrm{ABC}, \mathrm{ABC}, \ldots$ or

\section{ABAC, ABAC, ABAC}

In the first case, if the headway between vehicles on the trunk section is equal to $h$, the headway at the each branch is equal to $3 h$ (see time-space diagram in Fig. 1).

In the second case, if the headway between two vehicles at the trunk section $\mathrm{TX}$ is equal to $h$, the headways at the branches $\mathrm{XA}, \mathrm{XB}$ and $\mathrm{XC}$ respectively will be equal to $2 h, 4 h, 4 h$ (see time-space diagram in Fig. 2).

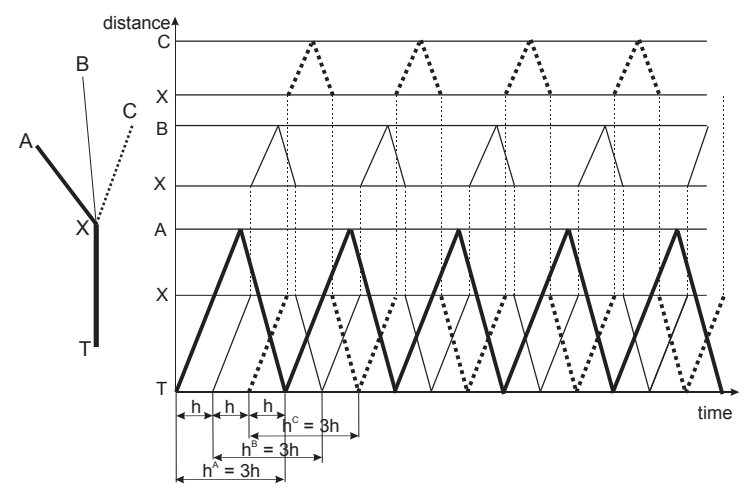

Fig. 1.

Operation of a Line with Three Branches Following the ABC Pattern of Departures from Terminus $T$ 


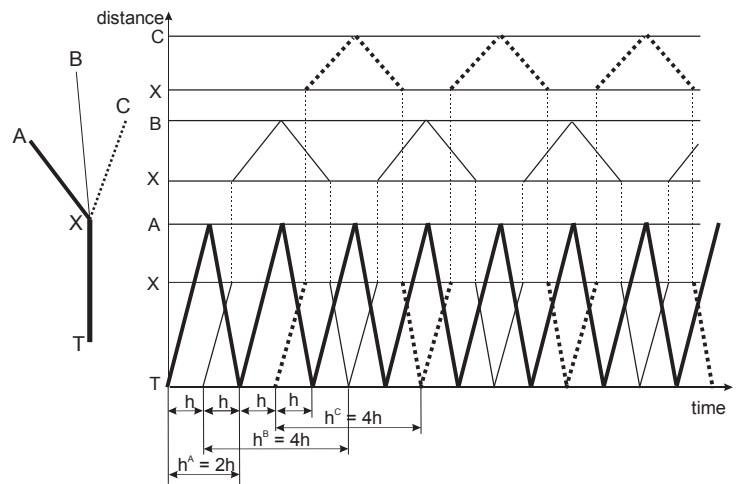

Fig. 2.

Operation of a Line with Three Branches Following the ABAC Pattern of Departures from Terminus $T$

\section{Modeling Uniform Headway Patterns for any Number of Branches}

The solution to the problem of uniform headway operation at all sections of a public transport line with $n$ branches more specifically requires:

- identification of possible patterns of departures from the starting terminus,

- determination of the possible number of patterns for uniform headway operation,

- computation of the headway for each line and the headway pattern at all sections of the line.

In order to identify the key variables and the mathematical relations that guarantee the uniform headway operation on a line with any number of branches, the number of possible cases are analyzed and presented in Table 1. It contains the basic sets of departures for a line with 2 to 7 branches.

These tables are enough to represent the existing patterns and are good base for developing general rules and mathematical relations for any number of branches.
Let us define the following terms and variables:

Basic set of departures is a set defined by the order of departures of public transport vehicles from the starting terminus. This pattern of departures repeats itself all the time during the operation of the line. Some of the line/branches may appear several times within the basic set, but this set contains at least two lines/branches that appear only once.

The basic set of departure must satisfy the requirement of uniform headways on each of the lines/branches.

Basic pattern of departures is a basic set of departures where each line/branch appears only once in orderly alternation. For example: $A B C D$ for a line with four branches, or $A B C D E F$ for a line with six branches.

Basic pattern of headways defines the headway for each branch for a given set of departures.

$h$ - headway between two successive vehicles on the trunk section of the line 
$h^{A}$ - headway between two successive vehicles on the brunch section of the line (for example branch A)

$m$ - number of lines/branches

$m_{1}$ - number of departures that are repeated $m_{2}$ times in the basic set

$m_{1}=1,2,3, \ldots m-1$

$m_{2}$ - number of departures in the basic set that appear only once

$m_{2}=1,2,3, \ldots m-1$

Note that

$m=m_{1}+m_{2}$

also note that for a basic patterns of headways the corresponding values of $m_{1}$ and $m_{2}$ will be

$m_{1}=m-1$

$m_{2}=1$

$r_{1}, r_{2}$ - factors of a $m_{2}$ if $m_{2}$ is a composite number where a composite number is a positive integer that has at least one positive divisor other than one or the number itself. In other words, a composite number is any positive integer greater than one, that is not a prime number.

For a composite number $m_{2}$ the following relation is valid

$$
m_{2}=r_{1} \cdot r_{2}
$$

and the meaning of the two factors is as follow:

$r_{1}$ is the number of departures out of $m_{2}$ that are repeated $r_{2}$ times in the basic set.
When $m_{2}$ is a prime number, then we agree that the following is true

$$
r_{1}=1 \text { and } r_{2}=m_{2}
$$

With these definitions in mind, from the patterns described in Tables 1 or 2 the following mathematical relations can be derived:

- Total number of basic sets of departures will be equal to:

$$
n=m-1 \quad \text { for } 2 \leq m \leq 4
$$

$n=(m-1)+\sum_{i=4}^{m-1} n_{i}^{c} \quad$ for $m>4$

where

$n$ - total number of basic sets of departures that guarantees uniform headway operation on all sections of the line

$n_{i}^{c}$ - number of ways that a composite number may be presented as $m_{2}=r_{1} r_{2}$ for all integer numbers $r_{1}, r_{2} \neq 1$ that are factors of that number.

Possible basic sets of departures for a line with $m$ branches can be obtain for $m_{1}=1,2,3, \ldots m-1$ departures from starting terminus that a repeated $m_{2}=m-m_{1}$ times in the basic set of departures plus the patterns obtained for $r_{2} \mathrm{x} r_{1}$ departures in the basic set if $m_{2}$ is a composite number.

\section{- Headway patterns}

Out of $m$ branches, $m_{1}$ lines will operate with headway equal to

$$
\left(m_{1}+r_{1}\right) h
$$

and $\mathrm{m}_{2}$ will operate with headway

$\left(m_{1} \cdot r_{2}+m_{2}\right) h$ 
Table 1

Different Basic Sets of Departures and Headway Patterns for a Line with $m$ Equal to 2 to 7 Branches

\begin{tabular}{|c|c|c|c|c|c|c|}
\hline \multirow[t]{3}{*}{$\mathrm{m}=2$} & $\begin{array}{l}\mathrm{AB} \\
2 \mathrm{~h}, 2 \mathrm{~h}\end{array}$ & & & & & \\
\hline & $\mathrm{m}_{1}=1$ & & & & & \\
\hline & $\mathrm{m}_{2}=1$ & & & & & \\
\hline \multirow[t]{3}{*}{$\mathrm{m}=3$} & $\begin{array}{l}\mathrm{ABC} \\
3 \mathrm{~h}, 3 \mathrm{~h}, 3 \mathrm{~h}\end{array}$ & $\begin{array}{l}\text { ABAC } \\
2 h, 4 h, 4 h\end{array}$ & & & & \\
\hline & $\mathrm{m}_{1}=2$ & $m_{1}=1$ & & & & \\
\hline & $m_{2}=1$ & $m_{2}=2$ & & & & \\
\hline \multirow[t]{3}{*}{$\mathrm{m}=4$} & $\begin{array}{l}\mathrm{ABCD} \\
4 \mathrm{~h}, 4 \mathrm{~h}, 4 \mathrm{~h}, 4 \mathrm{~h}\end{array}$ & $\begin{array}{l}\text { ABCABD } \\
3 \mathrm{~h}, 3 \mathrm{~h}, 6 \mathrm{~h}, 6 \mathrm{~h}\end{array}$ & $\begin{array}{l}\text { ABACAD } \\
2 \mathrm{~h}, 6 \mathrm{~h}, 6 \mathrm{~h}, 6 \mathrm{~h}\end{array}$ & & & \\
\hline & $\mathrm{m}_{1}=3$ & $m_{1}=2$ & $m_{1}=1$ & & & \\
\hline & $m_{2}=1$ & $m_{2}=2$ & $\mathrm{~m}_{2}=3$ & & & \\
\hline \multirow[t]{7}{*}{$\mathrm{m}=5$} & $\begin{array}{l}\mathrm{ABCDE} \\
5 \mathrm{~h}, 5 \mathrm{~h}, 5 \mathrm{~h}, 5 \mathrm{~h}, 5 \mathrm{~h}\end{array}$ & $\begin{array}{l}\text { ABCDABCE } \\
4 \mathrm{~h}, 4 \mathrm{~h}, 4 \mathrm{~h}, 8 \mathrm{~h}, 8 \mathrm{~h}\end{array}$ & $\begin{array}{l}\text { ABCABDABE } \\
3 \mathrm{~h}, 3 \mathrm{~h}, 9 \mathrm{~h}, 9 \mathrm{~h}, 9 \mathrm{~h}\end{array}$ & $\begin{array}{l}\text { ABACADAE } \\
2 \mathrm{~h}, 8 \mathrm{~h}, 8 \mathrm{~h}, 8 \mathrm{~h}, 8 \mathrm{~h}\end{array}$ & & \\
\hline & $\mathrm{m}_{1}=4$ & $\mathrm{~m}_{1}=3$ & $\mathrm{~m}_{1}=2$ & $\mathrm{~m}_{1}=1$ & & \\
\hline & $\mathrm{m}_{2}=1$ & $\mathrm{~m}_{2}=2$ & $\mathrm{~m}_{2}=3$ & $m_{2}=4$ composite no. & & \\
\hline & & & & $\begin{array}{l}\text { ABCADE } \\
\text { 3h,6h,6h,6h,6h }\end{array}$ & & \\
\hline & & & & $\mathrm{m}_{1}=1$ & & \\
\hline & & & & $r_{1}=2$ & & \\
\hline & & & & $\mathrm{r}_{2}=2$ & & \\
\hline \multirow[t]{7}{*}{$\mathrm{m}=6$} & $\begin{array}{l}\text { ABCDEF } \\
6 \mathrm{~h}, 6 \mathrm{~h}, 6 \mathrm{~h}, \\
6 \mathrm{~h}, 6 \mathrm{~h}, 6 \mathrm{~h}\end{array}$ & $\begin{array}{l}\mathrm{ABCDE} \\
\mathrm{ABCDF} \\
5 \mathrm{~h}, 5 \mathrm{~h}, 5 \mathrm{~h}, \\
5 \mathrm{~h}, 10 \mathrm{~h}, 10 \mathrm{~h} \\
\end{array}$ & $\begin{array}{l}\text { ABCDABCE } \\
\text { ABCF } \\
4 \mathrm{~h}, 4 \mathrm{~h}, 4 \mathrm{~h}, \\
12 \mathrm{~h}, 12 \mathrm{~h}, 12 \mathrm{~h} \\
\end{array}$ & $\begin{array}{l}\text { ABCABDABE } \\
\text { ABF } \\
3 \mathrm{~h}, 3 \mathrm{~h}, 12 \mathrm{~h}, 12 \mathrm{~h}, \\
12 \mathrm{~h}, 12 \mathrm{~h}\end{array}$ & $\begin{array}{l}\text { ABACAD } \\
\text { AEAF } \\
2 \mathrm{~h}, 10 \mathrm{~h}, 10 \mathrm{~h}, \\
10 \mathrm{~h}, 10 \mathrm{~h}, 10 \mathrm{~h} \\
\end{array}$ & \\
\hline & $\mathrm{m}_{1}=5$ & $\mathrm{~m}_{1}=4$ & $\mathrm{~m}_{1}=3$ & $\mathrm{~m}_{1}=2$ & $\mathrm{~m}_{1}=1$ & \\
\hline & $\mathrm{m}_{2}=1$ & $\mathrm{~m}_{2}=2$ & $m_{2}=3$ & $\mathrm{~m}_{2}=4$ composite no. & $m_{2}=5$ & \\
\hline & & & & $\begin{array}{l}\text { ABCDABEF } \\
4 \mathrm{~h}, 4 \mathrm{~h}, 8 \mathrm{~h}, 8 \mathrm{~h}, 8 \mathrm{~h}, 8 \mathrm{~h}\end{array}$ & & \\
\hline & & & & $\mathrm{m}_{1}=2$ & & \\
\hline & & & & $r_{1}=2$ & & \\
\hline & & & & $\mathrm{r}_{2}=2$ & & \\
\hline \multirow[t]{13}{*}{$\mathrm{m}=7$} & ABCDEFG & $\mathrm{ABCDEF}$ & ABCDEABCD & ABCDABCE & ABCABDABE & ABACADA \\
\hline & 7h,7h,7h,7h, & ABCDEG & FABCDG & ABCFABCG & ABFABG & EAFAG \\
\hline & $7 \mathrm{~h}, 7 \mathrm{~h}, 7 \mathrm{~h}$ & $\begin{array}{l}\text { 6h,6h,6h,6h, } \\
6 \mathrm{~h}, 12 \mathrm{~h}, 12 \mathrm{~h}\end{array}$ & $\begin{array}{l}5 \mathrm{~h}, 5 \mathrm{~h}, 5 \mathrm{~h}, 5 \mathrm{~h}, \\
15 \mathrm{~h}, 15 \mathrm{~h}, 15 \mathrm{~h}\end{array}$ & $\begin{array}{l}\text { 4h,4h,4h,16h, } \\
16 \mathrm{~h}, 16 \mathrm{~h}, 16 \mathrm{~h}\end{array}$ & $\begin{array}{l}3 \mathrm{~h}, 3 \mathrm{~h}, 15 \mathrm{~h}, 15 \mathrm{~h}, \\
15 \mathrm{~h}, 15 \mathrm{~h}, 15 \mathrm{~h}\end{array}$ & $\begin{array}{l}\text { 2h,12h,12h,12h, } \\
12 \mathrm{~h}, 12 \mathrm{~h}, 12 \mathrm{~h}\end{array}$ \\
\hline & $\mathrm{m}_{1}=6$ & $\mathrm{~m}_{1}=5$ & $\mathrm{~m}_{1}=4$ & $\mathrm{~m}_{1}=3$ & $\mathrm{~m}_{1}=2$ & $\mathrm{~m}_{1}=1$ \\
\hline & $\mathrm{m}_{2}=1$ & $\mathrm{~m}_{2}=2$ & $\mathrm{~m}_{2}=3$ & $m_{2}=4$ composite no. & $\mathrm{m}_{2}=5$ & $m_{2}=6$ composite no. \\
\hline & & & & $\begin{array}{l}\text { ABCDEABCFG } \\
5 \mathrm{~h}, 5 \mathrm{~h}, 5 \mathrm{~h}, 10 \mathrm{~h}, 10 \mathrm{~h}, \\
10 \mathrm{~h}, 10 \mathrm{~h}\end{array}$ & & $\begin{array}{l}\text { ABCADEAEF } \\
\text { 3h,9h,9h,9h,9h,9h, } \\
9 \mathrm{~h}\end{array}$ \\
\hline & & & & $\mathrm{m}_{1}=3$ & & $\mathrm{~m}_{1}=1$ \\
\hline & & & & $\mathrm{r}_{1}=2$ & & $r_{1}=2$ \\
\hline & & & & $\mathrm{r}_{2}=2$ & & $\mathrm{r}_{2}=3$ \\
\hline & & & & & & $\begin{array}{l}\text { ABCDAEFG } \\
4 \mathrm{~h}, 8 \mathrm{~h}, 8 \mathrm{~h}, 8 \mathrm{~h}, 8 \mathrm{~h}, 8 \mathrm{~h}, \\
8 \mathrm{~h}\end{array}$ \\
\hline & & & & & & $\mathrm{m}_{1}=1$ \\
\hline & & & & & & $\mathrm{r}_{1}=3$ \\
\hline & & & & & & $\mathrm{r}_{2}=2$ \\
\hline
\end{tabular}




\section{Example Case}

Let us consider a line with 10 branches. Then

$m_{2}=r_{1} \cdot r_{2}=2 \cdot 4$ or

$m_{2}=r_{1} \cdot r_{2}=4 \cdot 2$

$m=10$

$m_{1}=1,2,3 \ldots 9$

$m_{2}=1,2,3, \ldots 9$

so the number of ways to be represented as product of two factors is 2 .

$m_{2}$ is a composite number when it takes the For $m_{2}=9$ it can be factorized as

following values: $4,6,8$ and 9

When $m_{2}=4$ it can be factorized as

$$
m_{2}=r_{1} \cdot r_{2}=3 \cdot 3
$$

$$
m_{2}=r_{1} \cdot r_{2}=2 \cdot 2
$$

so the number of ways to be represented as product of two factors is 1 .

so the number of ways to be represented as

According to Eq. (7) the total number of basic sets of departures is:

product of two factors is 1 (for $r_{1}, r_{2} \neq 1$ ).

For $m_{2}=6$ it can be factorized as

$$
n=(m-1)+\sum_{i=4}^{m-1} n_{i}^{c}=(10-1)+(1+2+2+1)=15
$$

The basic sets of departures are determined $m_{2}=r_{1} \cdot r_{2}=2 \cdot 3$ or $m_{2}=r_{1} \cdot r_{2}=3 \cdot 2$ for all pairs of values for $m_{1}$ and $m_{2}=m$ $m_{1}\left(m_{1}=1,2,3 \ldots m-1\right)$ including the cases that arise from the possible permutations so the number of ways to be represented as product of two factors is 2 .

For $m_{2}=8$ it can be factorized as of factors of $m_{2}$ if $m_{2}$ is a composite number. The corresponding patterns of headways are computed by means of Eqs. (8) and (9). The results are presented in Table 2 . 
Table 2

Possible Basic Sets of Departures and Corresponding Patterns of Headways for a Line with 10 Branches

\begin{tabular}{|c|c|c|c|}
\hline Key variables & Basic set of departures & Headway patterns & \\
\hline $\begin{array}{l}m=10 \\
m_{l}=9 \\
m_{2}=1 \\
r_{1}=1 \\
r_{2}=1\end{array}$ & ABCDEFGHIJ & $\begin{array}{l}m_{1} \rightarrow\left(m_{1}+r_{1}\right) h \\
9 \rightarrow(9+1) h=10 h \\
9 \text { headways } 10 \mathrm{~h} \\
10 \mathrm{~h}, 10 \mathrm{~h}, 10 \mathrm{~h}, 10 \mathrm{~h}, 10 \mathrm{~h}, 10 \mathrm{~h}, 10 \mathrm{~h}, \\
10 \mathrm{~h}, 10 \mathrm{~h}\end{array}$ & $\begin{array}{l}m_{2} \rightarrow\left(m_{1} \cdot r_{2}+m_{2}\right) h \\
1 \rightarrow(9 \cdot 1+1) h=10 h \\
1 \text { headway } 10 \mathrm{~h} \\
10 \mathrm{~h}\end{array}$ \\
\hline $\begin{array}{l}m=10 \\
m_{l}=8 \\
m_{2}=2 \\
r_{l}=1 \\
r_{2}=2\end{array}$ & $\begin{array}{l}\text { ABCDEFGHI } \\
\text { ABCDEFGHJ }\end{array}$ & $\begin{array}{l}m_{1} \rightarrow\left(m_{1}+r_{1}\right) h \\
8 \rightarrow(8+1) h=9 h \\
8 \text { headways } 9 \mathrm{~h} \\
9 \mathrm{~h}, 9 \mathrm{~h}, 9 \mathrm{~h}, 9 \mathrm{~h}, 9 \mathrm{~h}, 9 \mathrm{~h}, 9 \mathrm{~h}, 9 \mathrm{~h}\end{array}$ & $\begin{array}{l}m_{2} \rightarrow\left(m_{1} \cdot r_{2}+m_{2}\right) h \\
2 \rightarrow(8 \cdot 2+2) h=18 h \\
2 \text { headways } 18 \mathrm{~h} \\
18 \mathrm{~h}, 18 \mathrm{~h}\end{array}$ \\
\hline $\begin{array}{l}m=10 \\
m_{1}=7 \\
m_{2}=3 \\
r_{1}=1 \\
r_{2}=3 \\
\end{array}$ & $\begin{array}{l}\text { ABCDEFGH } \\
\text { ABCDEFGI } \\
\text { ABCDEFGJ }\end{array}$ & $\begin{array}{l}m_{1} \rightarrow\left(m_{1}+r_{1}\right) h \\
7 \rightarrow(7+1) h=8 h \\
7 \text { headways } 8 \mathrm{~h} \\
8 \mathrm{~h}, 8 \mathrm{~h}, 8 \mathrm{~h}, 8 \mathrm{~h}, 8 \mathrm{~h}, 8 \mathrm{~h}, 8 \mathrm{~h}\end{array}$ & $\begin{array}{l}m_{2} \rightarrow\left(m_{1} \cdot r_{2}+m_{2}\right) h \\
3 \rightarrow(7 \cdot 3+3) h=24 h \\
3 \text { headways } 24 \mathrm{~h} \\
24 \mathrm{~h}, 24 \mathrm{~h}, 24 \mathrm{~h}\end{array}$ \\
\hline $\begin{array}{l}m=10 \\
m_{l}=6 \\
m_{2}=4 \\
r_{1}=1 \\
r_{2}=4\end{array}$ & $\begin{array}{l}\text { ABCDEFG } \\
\text { ABCDEFH } \\
\text { ABCDEFI } \\
\text { ABCDEFJ }\end{array}$ & $\begin{array}{l}m_{1} \rightarrow\left(m_{1}+r_{1}\right) h \\
6 \rightarrow(6+1) h=7 h \\
6 \text { headways } 7 \mathrm{~h} \\
7 \mathrm{~h}, 7 \mathrm{~h}, 7 \mathrm{~h}, 7 \mathrm{~h}, 7 \mathrm{~h}, 7 \mathrm{~h}\end{array}$ & $\begin{array}{l}m_{2} \rightarrow\left(m_{1} \cdot r_{2}+m_{2}\right) h \\
4 \rightarrow(6 \cdot 4+4) h=28 h \\
4 \text { headways } 28 \mathrm{~h} \\
28 \mathrm{~h}, 28 \mathrm{~h}, 28 \mathrm{~h}, 28 \mathrm{~h}\end{array}$ \\
\hline $\begin{array}{l}m=10 \\
m_{l}=6 \\
m_{2}=4 \text { composite } \\
\text { no. } \\
r_{l}=2 \\
r_{2}=2\end{array}$ & $\begin{array}{l}\text { ABCDEFGH } \\
\text { ABCDEFIJ }\end{array}$ & $\begin{array}{l}m_{1} \rightarrow\left(m_{1}+r_{1}\right) h \\
6 \rightarrow(6+2) h=8 h \\
6 \text { headways } 8 \mathrm{~h} \\
8 \mathrm{~h}, 8 \mathrm{~h}, 8 \mathrm{~h}, 8 \mathrm{~h}, 8 \mathrm{~h}, 8 \mathrm{~h}\end{array}$ & $\begin{array}{l}m_{2} \rightarrow\left(m_{1} \cdot r_{2}+m_{2}\right) h \\
4 \rightarrow(6 \cdot 2+4) h=16 h \\
4 \text { headways } 16 \mathrm{~h} \\
16 \mathrm{~h}, 16 \mathrm{~h}, 16 \mathrm{~h}, 16 \mathrm{~h}\end{array}$ \\
\hline $\begin{array}{l}m=10 \\
m_{l}=5 \\
m_{2}=5 \\
r_{l}=1 \\
r_{2}=5\end{array}$ & $\begin{array}{l}\text { ABCDEF } \\
\text { ABCDEG } \\
\text { ABCDEH } \\
\text { ABCDEI } \\
\text { ABCDEJ }\end{array}$ & $\begin{array}{l}m_{1} \rightarrow\left(m_{1}+r_{1}\right) h \\
5 \rightarrow(5+1) h=6 h \\
5 \text { headways } 6 \mathrm{~h} \\
6 \mathrm{~h}, 6 \mathrm{~h}, 6 \mathrm{~h}, 6 \mathrm{~h}, 6 \mathrm{~h}\end{array}$ & $\begin{array}{l}m_{2} \rightarrow\left(m_{1} \cdot r_{2}+m_{2}\right) h \\
5 \rightarrow(5 \cdot 5+5) h=30 h \\
5 \text { headways } 30 \mathrm{~h} \\
30 \mathrm{~h}, 30 \mathrm{~h}, 30 \mathrm{~h}, 30 \mathrm{~h}, 30 \mathrm{~h}\end{array}$ \\
\hline $\begin{array}{l}m=10 \\
m_{l}=4 \\
m_{2}=6 \\
r_{l}=1 \\
r_{2}=6\end{array}$ & $\begin{array}{l}\text { ABCDEABCDF } \\
\text { ABCDGABCDH } \\
\text { ABCDIABCDJ }\end{array}$ & $\begin{array}{l}m_{1} \rightarrow\left(m_{1}+r_{1}\right) h \\
4 \rightarrow(4+1) h=5 h \\
4 \text { headways } 5 \mathrm{~h} \\
5 \mathrm{~h}, 5 \mathrm{~h}, 5 \mathrm{~h}, 5 \mathrm{~h}\end{array}$ & $\begin{array}{l}m_{2} \rightarrow\left(m_{1} \cdot r_{2}+m_{2}\right) h \\
6 \rightarrow(4 \cdot 6+6) h=30 h \\
6 \text { headways } 30 \mathrm{~h} \\
30 \mathrm{~h}, 30 \mathrm{~h}, 30 \mathrm{~h}, 30 \mathrm{~h}, 30 \mathrm{~h}, 30 \mathrm{~h}\end{array}$ \\
\hline $\begin{array}{l}m=10 \\
m_{l}=4 \\
m_{2}=6 \text { composite } \\
\text { no. } \\
r_{l}=2 \\
\end{array}$ & $\begin{array}{l}\text { ABCDEF } \\
\text { ABCDGH } \\
\text { ABCDIJ }\end{array}$ & $\begin{array}{l}m_{1} \rightarrow\left(m_{1}+r_{1}\right) h \\
4 \rightarrow(4+2) h=6 h \\
4 \text { headways } 6 \mathrm{~h} \\
6 \mathrm{~h}, 6 \mathrm{~h}, 6 \mathrm{~h}, 6 \mathrm{~h}\end{array}$ & $\begin{array}{l}m_{2} \rightarrow\left(m_{1} \cdot r_{2}+m_{2}\right) h \\
6 \rightarrow(4 \cdot 3+6) h=18 h \\
6 \text { headways } 18 \mathrm{~h} \\
18 \mathrm{~h}, 18 \mathrm{~h}, 18 \mathrm{~h}, 18 \mathrm{~h}, 18 \mathrm{~h}, 18 \mathrm{~h}\end{array}$ \\
\hline$r_{2}=3$ & & & \\
\hline $\begin{array}{l}m=10 \\
m_{1}=4 \\
m_{2}=6 \text { composite } \\
\text { no. } \\
r_{l}=3 \\
r_{2}=2\end{array}$ & $\begin{array}{l}\text { ABCDEFG } \\
\text { ABCDHIJ }\end{array}$ & $\begin{array}{l}m_{1} \rightarrow\left(m_{1}+r_{1}\right) h \\
4 \rightarrow(4+3) h=7 h \\
4 \text { headways } 7 \mathrm{~h} \\
7 \mathrm{~h}, 7 \mathrm{~h}, 7 \mathrm{~h}, 7 \mathrm{~h}\end{array}$ & $\begin{array}{l}m_{2} \rightarrow\left(m_{1} \cdot r_{2}+m_{2}\right) h \\
6 \rightarrow(4 \cdot 2+6) h=14 h \\
6 \text { headways } 14 \mathrm{~h} \\
14 \mathrm{~h}, 14 \mathrm{~h}, 14 \mathrm{~h}, 14 \mathrm{~h}, 14 \mathrm{~h}, 14 \mathrm{~h}\end{array}$ \\
\hline $\begin{array}{l}m=10 \\
m_{1}=3 \\
m_{2}=7 \\
r_{l}=1 \\
r_{2}=7\end{array}$ & $\begin{array}{l}\text { ABCDABCEABCF } \\
\text { ABCGABCHABCI } \\
\text { ABCJ }\end{array}$ & $\begin{array}{l}m_{1} \rightarrow\left(m_{1}+r_{1}\right) h \\
3 \rightarrow(3+1) h=4 h \\
3 \text { headways } 4 \mathrm{~h} \\
4 \mathrm{~h}, 4 \mathrm{~h}, 4 \mathrm{~h}\end{array}$ & $\begin{array}{l}m_{2} \rightarrow\left(m_{1} \cdot r_{2}+m_{2}\right) h \\
7 \rightarrow(3 \cdot 7+7) h=28 h \\
7 \text { headways } 28 \mathrm{~h} \\
28 \mathrm{~h}, 28 \mathrm{~h}, 28 \mathrm{~h}, 28 \mathrm{~h}, 28 \mathrm{~h}, 28 \mathrm{~h}, 28 \mathrm{~h}\end{array}$ \\
\hline $\begin{array}{l}m=10 \\
m_{1}=2 \\
m_{2}=8 \\
r_{1}=1 \\
r_{2}=8\end{array}$ & $\begin{array}{l}\text { ABCABDABEABF } \\
\text { ABGABHABIABJ }\end{array}$ & $\begin{array}{l}m_{1} \rightarrow\left(m_{1}+r_{1}\right) h \\
2 \rightarrow(2+1) h=3 h \\
2 \text { headways } 3 \mathrm{~h} \\
3 \mathrm{~h}, 3 \mathrm{~h}\end{array}$ & $\begin{array}{l}m_{2} \rightarrow\left(m_{1} \cdot r_{2}+m_{2}\right) h \\
8 \rightarrow(2 \cdot 8+8) h=24 h \\
8 \text { headways } 24 \mathrm{~h} \\
24 \mathrm{~h}, 24 \mathrm{~h}, 24 \mathrm{~h}, 24 \mathrm{~h}, 24 \mathrm{~h}, 24 \mathrm{~h}, 24 \mathrm{~h}, 24 \mathrm{~h}\end{array}$ \\
\hline $\begin{array}{l}m=10 \\
m_{1}=2 \\
m_{2}=8 \text { composite } \\
\text { no. } \\
r_{l}=2 \\
r_{2}=4\end{array}$ & $\begin{array}{l}\text { ABCDABEFABGH } \\
\text { ABIJ }\end{array}$ & $\begin{array}{l}m_{1} \rightarrow\left(m_{1}+r_{1}\right) h \\
2 \rightarrow(2+2) h=4 h \\
2 \text { headways } 4 \mathrm{~h} \\
4 \mathrm{~h}, 4 \mathrm{~h}\end{array}$ & $\begin{array}{l}m_{2} \rightarrow\left(m_{1} \cdot r_{2}+m_{2}\right) h \\
8 \rightarrow(2 \cdot 4+8) h=16 h \\
8 \text { headways } 16 \mathrm{~h} \\
16 \mathrm{~h}, 16 \mathrm{~h}, 16 \mathrm{~h}, 16 \mathrm{~h}, 16 \mathrm{~h}, 16 \mathrm{~h}, 16 \mathrm{~h}, 16 \mathrm{~h}\end{array}$ \\
\hline $\begin{array}{l}m=10 \\
m_{l}=2 \\
m_{2}=8 \text { composite } \\
\text { no. } \\
r_{l}=4 \\
r_{2}=2\end{array}$ & $\begin{array}{l}\text { ABCDEFABCDGH } \\
\text { ABCDIJ }\end{array}$ & $\begin{array}{l}m_{1} \rightarrow\left(m_{1}+r_{1}\right) h \\
2 \rightarrow(2+4) h=6 h \\
2 \text { headways } 6 \mathrm{~h} \\
6 \mathrm{~h}, 6 \mathrm{~h}\end{array}$ & $\begin{array}{l}m_{2} \rightarrow\left(m_{1} \cdot r_{2}+m_{2}\right) h \\
8 \rightarrow(2 \cdot 2+8) h=12 \mathrm{~h} \\
8 \text { headways } 12 \mathrm{~h} \\
12 \mathrm{~h}, 12 \mathrm{~h}, 12 \mathrm{~h}, 12 \mathrm{~h}, 12 \mathrm{~h}, 12 \mathrm{~h}, 12 \mathrm{~h}, 12 \mathrm{~h}\end{array}$ \\
\hline $\begin{array}{l}m=10 \\
m_{1}=1 \\
m_{2}=9 \\
r_{l}=1 \\
r_{2}=9\end{array}$ & $\begin{array}{l}\text { ABACADAF } \\
\text { AGAHAIAJ }\end{array}$ & $\begin{array}{l}m_{1} \rightarrow\left(m_{1}+r_{1}\right) h \\
1 \rightarrow(1+1) h=2 h \\
1 \text { headway } 2 \mathrm{~h} \\
2 \mathrm{~h}\end{array}$ & $\begin{array}{l}m_{2} \rightarrow\left(m_{1} \cdot r_{2}+m_{2}\right) h \\
9 \rightarrow(1 \cdot 9+9) h=18 \mathrm{~h} \\
9 \text { headways } 18 \mathrm{~h} \\
18 \mathrm{~h}, 18 \mathrm{~h}, 18 \mathrm{~h}, 18 \mathrm{~h}, 18 \mathrm{~h}, 18 \mathrm{~h}, 18 \mathrm{~h}, \\
18 \mathrm{~h}, 18 \mathrm{~h}\end{array}$ \\
\hline $\begin{array}{l}m=10 \\
m_{l}=1 \\
m_{2}=9 \text { composite } \\
\text { no. } \\
r_{l}=3 \\
r_{2}=3\end{array}$ & ABCDAEFGAHIJ & $\begin{array}{l}m_{1} \rightarrow\left(m_{1}+r_{1}\right) h \\
1 \rightarrow(1+3) h=4 h \\
1 \text { headways } 4 \mathrm{~h} \\
4 \mathrm{~h}\end{array}$ & $\begin{array}{l}m_{2} \rightarrow\left(m_{1} \cdot r_{2}+m_{2}\right) h \\
9 \rightarrow(1 \cdot 3+9) h=12 \mathrm{~h} \\
9 \text { headways } 12 \mathrm{~h} \\
12 \mathrm{~h}, 12 \mathrm{~h}, 12 \mathrm{~h}, 12 \mathrm{~h}, 12 \mathrm{~h}, 12 \mathrm{~h}, 12 \mathrm{~h}, \\
12 \mathrm{~h}, 12 \mathrm{~h}\end{array}$ \\
\hline
\end{tabular}




\section{Conclusion}

The public transport line that branches at the outbound end of the line in some cases can be considered as best solution for providing good quality public transport service. If this is the case, it is recommended to schedule the line operation in a way that the vehicles will operate with uniform headways at all sections of the line. This is desirable due to the fact that the irregular headways can cause uneven loading of the public transport vehicles as well as uncertain waiting times for the passengers at stops.

However, the timetable planner must be aware that the uniform headway requirement at all sections of the line is not easy to achieve if reasonable utilization of the line capacity is to be maintained. This is due to the fact that only a specific number of departure sets and headway patterns are available for a given number of branches that may or may not correspond to the maximum passenger load patterns.

The analysis presented in this article focuses on the identification and determination of the possible patterns of departures and headways as well as the key variables and their relations that satisfy the requirement of uniform headway operation at all sections of a trunk with branches line. The presented results show the key variables that define the uniform headway operation and establish their relationships, thus providing answer to the question what headway patterns are feasible and if they could be acceptable for real life operation.

In general, the obtained results are to be valuable mostly to the public transport operators, but also to theorists in the field, as well to mathematicians who may find that the solution of this practical problem could lead to new discoveries in the theory of numbers.

\section{References}

Dodson, J.; Mees P.; Stone, J.; Burke, M. 2011. The Principles of Public Transport Network Planning: A review of the emerging literature with select examples, Urban Research Program, Issues Paper 15.

Guihaire, V.; Hao, J-K. 2008. Transit Network Design and Scheduling: A Global Review, Transportation Research Part A: Policy and Practice. DOI: http://dx.doi. org/10.1016/j.tra.2008.03.011, 42(10): 1251-1273.

Jiang, X.; Guo, X. 2014. Integrated Operation of Trunk Routes and Branches of Rural Transit. In Proceedings of the 9th International Conference on Traffic \& Transportation Studies (ICTTS'2014). DOI: http://dx.doi.org/10.1016/j. sbspro.2014.07.229, 138: 501-509.

Krstanoski, N. 2013. Scheduling trunk with branches public transport operation under the condition of uniform headway operation. In Proccedings of the $I V$ International Symposium NEW HORIZONS 2013 oftransport and communications, 22-23 November, Doboj, 13-17.

Shimamoto, H.; Schmocker, J.; Kurauchi, F. 2012. Optimisation of a Bus Network Optimization and Frequency Considering the Common Lines Problem, Journal of Transportation Technologies. DOI: http://dx.doi. org/10.4236/jtts.2012.23024, 2(3): 220-229.

Vuchic, V.R. 2002. Bus Semirapid Transit Mode Development and Evaluation, Journal of Public Transportation. DOI: http://dx.doi.org/10.5038/23750901.5.2.4, 5(2): 71-95.

Vuchic, V.R. 2005. Urban Public transport Operations, Planning and Economics. John Wiley \& Sons, USA. 